\title{
PW01-034 Clinical-genetic investigation of FMF in Armenia
}

\author{
H Hayrapetyan', G Amaryan², A Yeghiazaryan', T Sarkisian ${ }^{\text {1* }}$ \\ From 7th Congress of International Society of Systemic Auto-Inflammatory Diseases (ISSAID) \\ Lausanne, Switerland. 22-26 May 2013
}

\section{Introduction}

Familial Mediterranean Fever (FMF) is the most common hereditary disorder among Armenians. The establishment of clinical and genetic testing of FMF in the Center of Medical Genetics and Primary Health Care (CMG) was mostly forced by the high social and public health problems concerning a huge cohort of patients.

\section{Objectives}

Prevalence of FMF is 14-100/per 10000 in different regions of Armenia. Frequency of carriers of MEFV mutations is 1:3 in Armenians. And, the increase of the incidence of FMF and related disorders is caused by genetic drift and geographical isolation.

\section{Methods}

Molecular genetic detection of 12 MEFV mutations accounting for $98,71 \%$ of patients compared to healthy individuals revealed the most frequent genotypes and genotype-phenotype correlations.

\section{Results}

Heterozygote carriers associated with abortive and mild FMF features is $18,72 \%$, and $1.29 \%$ of patients with clinical features of FMF are without mutations. In some FMF patients "mild" MEFV mutations are associated with inflammatory attacks (P369S: 0.49\%; E148Q: 5.09\%; A744S: 0.74\%). Genotypes E148Q/A744S and E148Q/P369S are found rarely.

We have revealed the complex FMF cases with following concurrent morbidity: epilepsy (M694V/M694V; V726A/M680I); Sjogren syndrome (M694V/M694V); bronchial asthma (M694V/V726A, V726A/M680I, M680I); b-thalassemia (M694V/M694V); hyperthyroidism (M694V/M680I); Tourette syndrome (M694V/M694V);

${ }^{1}$ Center of Medical Genetics and Primary Health Care, Yerevan, Armenia Full list of author information is available at the end of the article
Ulcerative colitis (M694V/M694V); renal amyloidosis and multiple sclerosis (M680I/M680I); ankylosing spondilitislike syndrome in about $20 \%$ of FMF patients (predominantly M694V/M694V), etc.

We have shown that particular mutations have significant correlation with renal amyloidosis (RA). In frames of International Meta-FMF project we compared our data with the FMF morbidity among the other populations. We confirmed that M694V mutation is a high risk factor of RA in patients in Armenia, Israel, Lebanon, but not associated with RA in Turkey. M694V homozygous genotype of MEFV in FMF patients with RA is significantly higher than in patients without RA. The risk of male patients to develop RA is four times higher than that of female patients. SAA (Serum Amyloid A) a/a homozygous genotype is also associated with a seven-fold increased risk of developing RA, compared to other SAA1 genotypes. The presence of only one SAA1 a/a allele does not suggest an increased susceptibility to RA. In our cohort of FMF patients the adequate colchicine-therapy may delay RA progression. In a few cases, the effect of colchicine remains controversial. M694V homozygotes present a more severe phenotype and show a limited response to colchicine at the nephrotic stage of RA. In contrast, FMF patients with other genotypes still have a good chance to escape the nephrotic syndrome and to maintain renal function.

\section{Conclusion}

As a result of our 16-year experience, the CMG holds the largest DNA Biobank of FMF (more than 18000 samples). The number of patients visiting CMG is dramatically increasing due to complex clinical and genetic examinations, assessment of efficiency of colchicine treatment, prognosis of development of complications, including renal amyloidosis, counseling of families, professional and public awareness. Genetic counseling of FMF patients and 
their families is performed for the disease risk estimation for future generations.

\section{Disclosure of interest}

None declared.

\section{Authors' details}

'Center of Medical Genetics and Primary Health Care, Yerevan, Armenia. ${ }^{2}$ Arabkir Joint Medical Centre - Institute of Child and Adolescent Health, Yerevan, Armenia.

Published: 8 November 2013

doi:10.1186/1546-0096-11-S1-A87

Cite this article as: Hayrapetyan et al:: PW01-034 Clinical-genetic

investigation of FMF in Armenia. Pediatric Rheumatology 2013 11(Suppl 1): A87.

Submit your next manuscript to BioMed Central and take full advantage of:

- Convenient online submission

- Thorough peer review

- No space constraints or color figure charges

- Immediate publication on acceptance

- Inclusion in PubMed, CAS, Scopus and Google Scholar

- Research which is freely available for redistribution 